\title{
Recommendations for Making Judgements about Total Market Value in the Evaluation of Interests in Companies
}

Yuri V Kozyr*

Central Economics and Mathematics Institute of Russian Academy of Sciences, Moscow, Ruaaian Federation, Russia

\begin{abstract}
The purpose of this paper is to reflect the author's views on the methodology of final grades in the evaluation of shares in the company based on the results of the use of multiple valuation approaches. In contrast to the widespread use of information, evaluation results obtained from the use of different evaluation approaches, by their weighting is proposed to establish upper and lower bounds of property being valued. The presence of these borders is due to the logic of rational behavior of economic (economic) entities as well as the provisions of the current edition of the International Valuation Standards. A further mechanism for obtaining the final valuations of shares in companies similar to the traditional. In general, the proposals made in the work permit to get a more informed assessment of the total value of shares in the companies.
\end{abstract}

Keywords: Business valuation; Preliminary cost; Total cost; The results of evaluation approaches

Classification JEL: D46, G12, G13.

\section{Introduction}

As you know, the evaluation professional appraisers generally use multiple valuation approaches - expensive, comparative and profitable. After receiving the results of the calculations in the framework of these approaches, several interim valuations, appraisers then output the final judgment on the value of the property valuation. For this purpose, usually the following mechanisms were used

Subjective weighting method (Most often applicable), within which the evaluators on the basis of various arguments and/or analysis of data series have come to believe about the significance of the results of evaluation approaches, while appointing an interim assessment received the appropriate weight, the amount of which is equal to one;

Analytic hierarchy process is a mechanism for ranking the quality properties and attributes used in the calculation of the estimated approaches, the use of which may be justified by using at least three valuation approaches when direct analysis of the quality of the results obtained in the different approaches leads to mixed results [1].

(For example, the quality of the i-th property/attribute in the cost approach is better than the quality of the same property in the income approach, the quality of the $\mathrm{i}$-th property/attribute in the income approach is better than the quality of the same property in a comparative approach, but the quality of the i-th property/attribute in the cost approach is worse than the quality of the same properties in the comparative approach);

Choice as the total value of the result of one of the approaches Such a mechanism is most often used in the estimates for reflection IFRS. According to the author of this article, in deriving judgments about the total value is a certain "tunnel vision" views: choosing one or another way to harmonize approaches, evaluators are not thinking more about what motivates potential parties to the transaction (if it is determined the market value) and how quickly and with the least effort to complete the project, guided by such arguments as "everyone does it", "it is written in the textbook evaluation" or - in the evaluation policy to reflect IFRS - "according to the standards". Below is a look at the problem of estimation of the final value of the objects from the perspective of assessing the reality of the transaction at a price that reflected in the evaluation report, and reflects the author's vision problems [2].

\section{Features of determining the market value of different approaches}

To start we will go to the well-known theory and practice of assessment, the underlying application of valuation approaches in the evaluation of interests in companies. Why do we apply these approaches?

As is known, the use of comparative (or any other "market") approach is the idea that if somewhere recently fixed price deals with object-analogue, the price of the deal after the implementation of a number of adjustments to reflect the difference between the properties of the object being evaluated an analogue thereof may be used to obtain the estimated value of the object. In applying the so-called cost approach is the idea that if offered by companies or business can "build from scratch", thus creating an equivalent set (ensemble) of assets and liabilities, the price of such transactions shall not exceed the cost of creating this ensemble (substitution principle) [3].

In applying the income approach is the idea that the price of the purchase and sale of a functioning company/business should be the equivalent present value of expected future net cash income from the operation of this company/business. Now, we should recall some features of the concept of "market value." In the interpretation of this concept, as set out in para 31 Principles International Valuation Standards (ed. 2011), in particular, said: "This is the price-the best attainable at reasonable reasons for the seller and the most profitable of the achievable on reasonable grounds, to the buyer" [4].

${ }^{*}$ Corresponding author: Kozyr Y, Central Institute for Economics and Mathematic Experimental Economics, 47 Narhimovsky prospect Moscow, Moscow 117270 , Russian Federation, Tel: +7(495)649-9375; Fax: +7(495)779-1324; E-mail: kozyr65@rambler.ru

Received May 04, 2015; Accepted August 19, 2015; Published August 21, 2015

Citation: Kozyr YV (2015) Recommendations for Making Judgements about Total Market Value in the Evaluation of Interests in Companies. Review Pub Administration Manag 3: 161. doi:10.4172/2315-7844.1000161

Copyright: (C) 2015 Kozyr YV. This is an open-access article distributed under the terms of the Creative Commons Attribution License, which permits unrestricted use, distribution, and reproduction in any medium, provided the original author and source are credited. 


\section{The range of values of market value}

Let's ask the question: under what conditions/circumstances, parties to the transaction (the owner of the object and estimates the buyer) can arrange the transaction price? On this question there is, generally speaking, two types of answers that reflect the different motivations of the parties.

According to the first type of response, based on each specific transaction are investment motives parties to the transaction. Accordingly, if the market is the object of evaluation is developed, the transaction price is the market price of the property valuation [5]. If the market valuation object is not developed, the transaction takes place, if the transaction price will lie within the range extending from the assessment of the investment project cost estimate of its own to assess the investment value of the object a potential buyer In other Words, the transaction takes place, if the minimum price at which the seller agrees to be lower or equal to the maximum price the buyer is willing to pay. If as a result of the emerging transaction takes place above mentioned intersection estimates the investment value of the seller and the buyer, the specific transaction price will be determined by the bargaining power of the parties and aspects of structuring the transaction. In turn, the bargaining power of the parties depends not so much on the skills of the negotiators, but on the basis of market positioning with the positioning of competitors. Much depends on the state of the market - whether there is market boom or recession, accordingly, whether at the time of the transaction market sellers or buyers. Depending on this, negotiating position, other things being equal, will be stronger in one of the parties who are in the market less, which means that the approach of the transaction price within the above range to the evaluation of the investment value of the hand [6]. In accordance with this method, it is necessary to use preliminary estimates of investment costs the owner(s) of the object and its evaluation of potential buyers for/to obtain the final estimate of the market value of the evaluation. This method is applicable, if the exact number of potential buyers (with a limited market or inability to exercise public offer) and true (reliable) information about their opinion (and the opinion of the seller) on the value of the investment value of the potential subject of the transaction (object value) At the same time, this method cannot be applied in cases where it is necessary to make an assessment at a future date, and is difficult for practical application, if necessary to assess the distant past date [7].

The second type of response to the question about the conditions of the deal, based on analysis of the value of the subject being evaluated, the state's financial and economic activity of the company, as well as the relationship between the results obtained by evaluation approaches.

- In assessing the non-controlling interests in joint stock companies should consider further whether the estimated shares quoted or not (how to do it - see. The following Table 1).

- Evaluation modalities of implementation of a potential deal with controlling stakes, as above, is based on the intersection of price ranges seller and the buyer of the best, and for each party to the transaction price will be determined by the following conditions:

- $\quad$ For the seller (the owner of the object assessment): $\mathrm{V}_{\mathrm{s}}=\max$ $\left[\mathrm{V}_{\mathrm{LV}} ; \mathrm{V}_{\mathrm{IAs}} ; \mathrm{V}_{\mathrm{CA}}\right] ;(1)$

- User: $\mathrm{V}_{\mathrm{b}}=\min \left[\mathrm{V}_{\mathrm{IAb}} ; \mathrm{V}_{\mathrm{CA}} ; \mathrm{V}_{\mathrm{ARCM}}\right]$

- where $\mathrm{V}_{\mathrm{s}}$ - reasonable price for the seller,

- $\mathrm{V}_{\mathrm{b}}$ - the acceptable price for the buyer,

- $\mathrm{V}_{\mathrm{IA}}$ - assessment of the value of the estimates obtained under the income approach,

- $\mathrm{V}_{\mathrm{LV}}$ - assessment of the value of the estimates obtained by the method of determining the value of a business when deciding on its liquidation (closing business interruption),

- $\mathrm{V}_{\mathrm{CA}}$ - assessment of the value of the estimates obtained under the comparative (market) approach,

- $\mathrm{V}_{\mathrm{IAs}}$ - assessment of the value obtained by the owner of the object assessment under the income approach,

- $\mathrm{V}_{\mathrm{IAb}}$ - assessment of the value obtained potential buyer object assessment under the income approach,

$\mathrm{V}_{\mathrm{ARCM}}$ - assessment of the value obtained in the framework of Assets

\begin{tabular}{|c|c|c|c|c|c|}
\hline \multirow[t]{3}{*}{ Situation } & \multicolumn{5}{|c|}{ Scope of assessment } \\
\hline & \multicolumn{3}{|c|}{ Controlling stakes/interest } & \multicolumn{2}{|c|}{ Non-controlling/interest inequity } \\
\hline & \multicolumn{2}{|c|}{$\begin{array}{l}\text { The ratio between } \\
\text { the results of } \\
\text { approaches }\end{array}$} & $\begin{array}{l}\text { Recommendations for } \\
\text { determining } \\
\text { the total value }\left(V_{F}\right)\end{array}$ & $\begin{array}{l}\text { Recommendations for } \\
\text { determining the total value } \\
\left(\mathrm{V}_{\mathrm{F}}\right) \text { for listed securities }\end{array}$ & $\begin{array}{l}\text { Recommendations for determining } \\
\text { the total value }\left(V_{F}\right) \text { for unlisted shares/ } \\
\text { interests }\end{array}$ \\
\hline \multirow{6}{*}{$\begin{array}{l}\text { Bankruptcy there } \\
\text { is not } \\
\text { expected }\end{array}$} & \multirow[t]{3}{*}{$\mathrm{V}_{C O A}<\mathrm{V}_{I A}$} & & $\begin{array}{l}\text { Should apply } \\
\text { ARCM }\end{array}$ & \multirow{6}{*}{$\begin{array}{l}\qquad \mathrm{V}_{F}=\mathrm{V}_{C A} \\
\text { If the packet size } \geq 10 \% \text { of } \\
\text { share capital may need to } \\
\text { apply a small } \\
\text { Correction (usually } \\
\text { premium) to the } \\
\text { quotations } \\
\text { relating to shares in the } \\
\text { composition of exchange } \\
\text { standard lots) }\end{array}$} & \multirow{6}{*}{$\begin{array}{l}\qquad \mathrm{V}_{F}=\mathrm{W}_{C A} \times \mathrm{V}_{C A} \\
+\mathrm{W}_{I A} \times \mathrm{V}_{I A} \\
\text { (comparative } \\
\text { approach must be based on the } \\
\text { transactions of comparable size stakes } \\
\text { peers. When packets of less than } \\
10 \% \text { of } \\
\text { share capital is better to use a modified } \\
\text { dividend discount model) }\end{array}$} \\
\hline & & $\mathrm{V}_{A R C M}<\mathrm{V}_{I A}$ & $\mathrm{~V}_{F}=\mathrm{V}_{A R C M}$ & & \\
\hline & & $\mathrm{V}_{I A} \ll \mathrm{V}_{A R C M}$ & $\mathrm{~V}_{F}=\mathrm{V}_{I A}$ & & \\
\hline & \multirow[t]{3}{*}{$\mathrm{V}_{I A}<\mathrm{V}_{C O A}$} & & $\begin{array}{l}\text { As part of the CoA should } \\
\text { further assess } V_{L V}\end{array}$ & & \\
\hline & & $V_{L V}<V_{I A}$ & $\mathrm{~V}_{F}=\mathrm{V}_{I A}$ & & \\
\hline & & $\mathrm{V}_{I A}<\mathrm{V}_{L V}$ & $\begin{array}{l}\mathrm{V}_{F}=\mathrm{V}_{L V} \\
\text { (If not exist good } \\
\text { possibilities of business } \\
\text { reorganization) }\end{array}$ & & \\
\hline $\begin{array}{l}\text { Verge of } \\
\text { bankruptcy }\end{array}$ & \multicolumn{2}{|c|}{$\begin{array}{l}\mathrm{V}_{L V}<\mathrm{V}_{I A} \\
\mathrm{~V}_{I A}<\mathrm{V}_{L V}\end{array}$} & $\begin{array}{c}\mathrm{V}_{F}=\mathrm{W}_{L V} \times \mathrm{V}_{L V}+\mathrm{W}_{I A} \times \mathrm{V}_{I A} \\
\mathrm{~V}_{F}=\mathrm{V}_{L V} \\
\text { (See note } \\
\text { below) }\end{array}$ & $\begin{array}{l}\text { if } \mathrm{V}_{L V}<\mathrm{V}_{C A}: \mathrm{V}_{F}=\mathrm{V}_{C A} \\
\text { if } \mathrm{V}_{C A}<\mathrm{V}_{L V}: \\
\mathrm{V}_{F}=\mathrm{V}_{L V} \\
\text { - In other } \\
\text { cases: } \mathrm{V}_{F}=\mathrm{V}_{C A}\end{array}$ & $\begin{array}{c}\mathrm{V}_{F}=\mathrm{W}_{C A} \times \mathrm{V}_{C A}+ \\
\mathrm{W}_{C A} \times \mathrm{V}_{C A} \geq \mathrm{V}_{L V} \\
\text { (comparative approach should reflect } \\
\text { condition of analogues close to } \\
\text { bankruptcy) }\end{array}$ \\
\hline State bankruptcy & \multicolumn{2}{|c|}{ Applicable only method of liquidation value } & $V_{F}=V_{L V}$ & $\mathrm{~V}_{F}=\mathrm{V}_{L V}$ & $\mathrm{~V}_{F}=\mathrm{V}_{L V}$ \\
\hline
\end{tabular}

Table 1: Recommendations for use of evaluation approaches and obtain the final (total) value. 
Replacement Cost Method ${ }^{1}$ (formally related to the cost approach, but is actually a hybrid of cost to income approaches) (Kozyr, Tabakova, Deuce $)^{2}$.

It should be noted that the strategically important companies usually cannot take into account the $\mathrm{V}_{\mathrm{LV}}$, so for them instead of (1) the condition for the seller must have the form:

$$
\mathrm{V}_{\mathrm{s}}=\max \left[\mathrm{V}_{\mathrm{IAs}} ; \mathrm{V}_{\mathrm{CA}}\right] \text {. }
$$

The basis of the above -defined and conditions, in addition to general economic logic, based on the following arguments.

1. According to the interpretation of the basis of market value (IVS -2011, 2013, Principles of IVS, market value, p. 31), the term "estimated amount" refers to the "terms of money price which may be paid for an asset at a commercial market transaction. This is the price - the best attainable at reasonable grounds for the seller and the most advantageous attainable at reasonable grounds for the buyer "(emphasis added) [8].

2. According to the interpretation of the basis of market value (IVS -2011, 2013, Principles of IVS, market value, p. 31), the term "between a willing buyer" refers to those who have reasons to buy, but it is nothing to it does not force. Such purchaser is not eager to buy and is not intended to pay any price. assumed buyer would not pay a price higher than what the market demands. The current owner of the asset is also included in the number of those who make up this "market" (emphasis added).

3. According to (IVS-2011, 2013, IVS 200, business and the right to participate in the business, $n$. 4), "if the evaluation is related to the rights granted the possibility to liquidate assets of a business, you should consider whether the aggregate value of assets in the event of sale separately in the liquidation business exceed the total value of the business as a going concern."

Taking into account the situation (IVS-2011, 2013, Principles of IVS, p. 63): "cost approach provides an index value based on the use of economic principle that the buyer will not pay for an asset is greater than the sum of the costs necessary to obtain an asset of equal usefulness, whether through its purchase or construction "(italics author), condition (2) literally means that

$$
\mathrm{V}_{\mathrm{b}}=\min \left[\mathrm{V}_{\mathrm{CA}} ; \mathrm{V}_{\mathrm{ARCM}}\right]
$$

However, taking into account the interpretation of para. 31 (a) ("It is the price - The most profitable of the achievable at reasonable grounds for the buyer"), it is obvious that it is the condition (2) best reflects the abovementioned circumstances It should be noted that usually when assessing controlling interests wording of the final judgments about the value of their value under the above conditions (1) - (2) is limited to the analysis based on the results of the income and cost approaches. On the contrary - deducing judgments about the total value of noncontrolling interests in the authorized capital of successful companies practically excludes consideration of the evaluation results obtained through the application of the cost approach (method of liquidation value $\left(\mathrm{V}_{\mathrm{LV}}\right)$ and the method of economic asset substitution $\left(\mathrm{V}_{\mathrm{ARCM}}\right)$ ), because on the one hand, the minority shareholders do not have the authority for making decisions about the close of business on the other

11 This valuation method relies on the replacement concept, according to which the investor will not pay more for an asset than the total cost necessary to create an asset of equal utility, be it by means of acquisition or construction.

${ }^{2}$ Here, the control stakes/interests implied stakes/interests, offers its owners a liquidation of the assets of business-approx. auth. hand, they do not make sense as an alternative to the acquisition of non-controlling interest participation in business to consider the replacement of all assets of a business by its creation "from scratch". Based on the definition of the category of the market value (aimed at implementing a deal with the estimated property), we can reasonably expect that the market value of the estimated object evaluation will meet the conditions of the transaction of sale. Having considered the controlling interest, it can be argued that in view of (1)-(2) the conditions for transactions exist in the following ratio between the preliminary results of the assessment:

$$
\begin{aligned}
& \left\{\mathrm{V}_{\mathrm{LV}} ; \mathrm{V}_{\text {IAs }}\right\} \leq \mathrm{V}_{\mathrm{CA}} \leq \mathrm{V}_{\text {IAb }}<\mathrm{V}_{\text {ARCM }}, \\
& \left\{\mathrm{V}_{\text {LV }} ; \mathrm{V}_{\text {IAs }}\right\} \leq \mathrm{V}_{\text {IAb }} \leq \mathrm{V}_{\mathrm{CA}}<\mathrm{V}_{\text {ARCM }}, \\
& \left\{\mathrm{V}_{\text {LV }} ; \mathrm{V}_{\text {IAs }}\right\} \leq \mathrm{V}_{\text {ARCM }} \leq \mathrm{V}_{\text {IAb }} \leq \mathrm{V}_{\text {CA }}, \\
& \mathrm{V}_{\mathrm{CA}} \leq \mathrm{V}_{\text {IAs }} \leq \mathrm{V}_{\text {LV }} \leq \mathrm{V}_{\text {IAb }} \leq \mathrm{V}_{\text {ARCM }} .
\end{aligned}
$$

- In the case when one of the relations (5) - (8) the expected transaction price will be close to the value of the corresponding estimate in italics, namely, the price of the transaction:

- at $\left\{\mathrm{V}_{\mathrm{LV}} ; \mathrm{V}_{\mathrm{IAS}}\right\} \leq \mathrm{V}_{\mathrm{CA}} \leq \mathrm{V}_{\mathrm{IAb}}<\mathrm{V}_{\mathrm{ARCM}}$ - will be close to the estimated values in the range $\left\{\mathrm{V}_{\mathrm{IAs}} ; \mathrm{V}_{\mathrm{IAb}}\right\}$, ie, primarily to estimate $\mathrm{V}_{\mathrm{CA}}$;

- at $\left\{\mathrm{V}_{\mathrm{LV}} ; \mathrm{V}_{\mathrm{IAs}}\right\} \leq \mathrm{V}_{\mathrm{IAb}} \leq \mathrm{V}_{\mathrm{CA}}<\mathrm{V}_{\mathrm{ARCM}}$ - will gravitate to the

- at $\left\{\mathrm{V}_{\mathrm{LV}} ; \mathrm{V}_{\mathrm{IAS}}\right\} \leq \mathrm{V}_{\mathrm{ARCM}} \leq \mathrm{V}_{\mathrm{IAb}} \leq \mathrm{V}_{\mathrm{CA}}$ - will gravitate to the value VARCM (less than or equal to);

- at $\mathrm{V}_{\mathrm{CA}} \leq \mathrm{V}_{\mathrm{IAs}} \leq \mathrm{V}_{\mathrm{LV}} \leq \mathrm{V}_{\mathrm{IAb}} \leq \mathrm{V}_{\mathrm{ARCM}}$ - will be in the range $\left\{\mathrm{V}_{\mathrm{LV}}\right.$; $\left.\mathrm{V}_{\mathrm{IAb}}\right\}$.

If there is the relation:

$\mathrm{V}_{\mathrm{LV}} \leq \mathrm{V}_{\mathrm{IAb}} \leq \mathrm{V}_{\mathrm{IAs}} \leq \mathrm{V}_{\mathrm{CA}} \leq \mathrm{V}_{\mathrm{ARCM}}$,

implementation of the transaction will be called into question; in the case of a positive outcome, the transaction price will be in the range $\left\{\mathrm{V}_{\mathrm{IAb}} ; \mathrm{V}_{\mathrm{CA}}\right\}$ is likely close to the estimate $\mathrm{V}_{\mathrm{IAs}}$.

In accordance with the remark made earlier, in the case of evaluation of control e lei participation of strategically important enterprises in the above inequalities should be excluded accounting valuation liquidation $\mathrm{V}_{\mathrm{LV}}$.

Application conditions (1)-(9) to derive the final judgments about the value of the stand of the relevant facilities assessment in general leads to a consideration of the 5-dimensional space of the preliminary cost: $\left\{\mathrm{V}_{\mathrm{LV}} ; \mathrm{V}_{\mathrm{IAs}} ; \mathrm{V}_{\mathrm{CA}} ; \mathrm{V}_{\mathrm{IAb}} ; \mathrm{V}_{\mathrm{ARCM}}\right\}$ for which there are $5 !=120$ variants of relations between these preliminary findings. Of this number should exclude all estimates $\left\{\mathrm{V}_{\mathrm{i}}\right\}<\mathrm{V}_{\mathrm{LV}}$ and most estimates in the range of $\left\{\mathrm{V}_{\mathrm{i}}\right\}>\mathrm{V}_{\mathrm{ARCM}}$. Because in reality, under the income approach, instead of two estimates $\left(\mathrm{V}_{\text {IAs }}\right.$ and $\left.\mathrm{V}_{\mathrm{IAb}}\right)$ usually use only one estimate $\left(\mathrm{V}_{\mathrm{IA}}\right)$ performed by an independent appraiser, 5-dimensional space costs narrowed to 4 -dimensional with $24 \mathrm{~h}$ in can embodiments of relations between them [9].

It is also important to note that often when agreeing the results of evaluations evaluators apply the control premium or a discount for lack of control, subject to agreement of results reflecting a common base value (or in the control of non-controlling levels). The use of such amendment is justified, if the basis of a pre-existing in the various valuation approaches results differ from each other and/or different from the base object of evaluation. However, the available empirical research on the subject of the values of these premiums and discounts 
are characterized by their enormous range $(+/-90 \%)$, which reduces the accuracy and validity of the total value of the object of evaluation when applied in the calculations. In this regard, the author of this article we recommend that you avoid using in the calculation of premiums and discounts for control-namely, in the framework of evaluation approaches should immediately assess the value of the subject being evaluated in a given assessment basis, which coincides with the required basis for evaluation of the subject being evaluated, reflecting the magnitude of the estimated interest and the distribution of shares of other participants (e.g. valuation of controlling stakes should be based on the cost approach and the income approach, excluding possible dividend discount method, the valuation of minority should be based primarily a comparative approach and, in some cases, the income approach, preferably with the use of the dividend discount model) [10].

Conditions (1)-(2) in the absence of the results of the application of one of the valuation approaches should/can appropriately "shrink" (Table 1).

The above arguments of the author in the "second type of response to the question about the conditions of the deal" more details are presented below in tabular form Table 1, where for the sake of completeness also presents cases of coordination of value for minority stakes. When completing this table was made an implicit assumption that when assessing control of shares comparative approach is not applied. Adopted in the table of symbols: « $\mathrm{V}_{\mathrm{CA}}$ » - result of an estimate, obtained in the framework's comparative approach, « $\mathrm{V}_{\mathrm{IA}}$ " - result of an estimate, obtained in the framework's income approach, " $\mathrm{V}_{\mathrm{CoA}}$ " - result of an estimate, obtained in the framework's cost approach, " $\mathrm{V}_{\mathrm{LV}}$ " - result of an estimate, obtained in the framework's the cost of liquidation business approach, « $\mathrm{V}_{\mathrm{ARCM}}$ " - result of an estimate, obtained in the framework's the modified cost approach (ARCM- method), $\mathrm{w}_{\mathrm{i}}-$ the significance (weight) of the $\mathrm{i}$ approach $\left(0<\mathrm{w}_{\mathrm{i}}<1, \Sigma \mathrm{w}_{\mathrm{i}}=1\right)$.

\section{with remarks.}

In assessing the controlling interests in situations where $\mathrm{V}_{\mathrm{IA}}<\mathrm{V}_{\mathrm{LV}}$, in some cases, the final cost of the project evaluation may differ from the proportional cost of closing (liquidation) business. This occurs when satisfied simultaneously the following two conditions:

- $\mathrm{V}_{\mathrm{IA}}<\mathrm{V}_{\mathrm{LV}}<\mathrm{V}_{\mathrm{IA}} \times(1+\operatorname{pr}(\mathrm{n}))$,

- $\operatorname{pr}(\mathrm{n})>\left(\mathrm{V}_{\mathrm{LV}} / \mathrm{V}_{\mathrm{IA}}-1\right)$,

where $n$ - the size of a controlling stake in the authorized capital (\% $100), \operatorname{pr}(\mathrm{n})$ - premium for the transition from the proportional value of $100 \%$ equity/share (estimated at the $100 \%$ control level) to the value on the controlling interest, defined as follows:

$$
\operatorname{pr}(n)=\frac{n^{*} M C A P+a^{*} C V}{n^{\star} M C A P_{C}}-1,
$$

where MCAP - market capitalization (value of $100 \%$ stake in the authorized capital of the company), excluding the value of control, MCAPc - market capitalization (value of $100 \%$ stake in the authorized capital of the company), including the value of control, a - the proportion of the control attributable to controlling interest $(0,51<\mathrm{a}$ $\leq 1), \mathrm{CV}$ - cost (value) of total control over the company (CV=MCAPc - MCAP).

For more information on entering into (12) the parameters can be found in ${ }^{2,3}$.

When that condition (10) - (11) the controlling shareholders will not close the business, despite the current situation $\mathrm{V}_{\mathrm{IA}}<\mathrm{V}_{\mathrm{LV}}$, as a result of their capacities for "pulling the blanket income" over the value of their share of the cost exceeded sit on they could expect in the event of liquidation of the business $\left(n \times V_{L V}\right)$, ie continued operation of the business is more profitable for them to eliminate it. Accordingly, when the feasibility of (10) - (11) the total value of $n \%$ controlling stake (interest) will be equal:

$$
\mathrm{V}_{\mathrm{F}}(\mathrm{n})=\mathrm{n} \times \mathrm{V}_{\mathrm{IA}} \times(1+\operatorname{pr}(\mathrm{n}))>\mathrm{V}_{\mathrm{LV}} .
$$

It is necessary to give some comments about recommendations presented in Table 1.

Cost evaluation of large objects (which are the controlling interest), which initially is not obvious, must be determined at the intersection of possible price the seller and buyer ${ }^{4},{ }^{5}$. From the standpoint of common sense, the minimum price at which shareholders may agree, is the price equivalent to the cost of closing (liquidation) business shareholders $\left(\mathrm{V}_{\mathrm{LV}}\right)$. Proof of this can be regarded as n. 4 "Assessment (IVS 102)" (see. IVS 200 "Business and the right to participate in the business), which reads as follows:" If the assessment is related to the rights granted by the elimination of business opportunity, you should consider whether the aggregate value of the assets in the business are sold separately in the liquidation of the business exceed the total value of the business as a going concern enterprise. "Similarly, the maximum price that the buyer agrees to pay the rational, the price is equivalent to the actual replacement cost of all the net assets of the company, taking into account the time needed to" build from scratch "business similar to the business target firm $\left(\mathrm{V}_{\mathrm{ARCM}}\right)$. If the result of the valuation of the controlling interest, carried out under the income approach fell within the above range, the lower and upper limits of this range will not have a decisive influence on the total value-the final result of evaluation will be the result of applying the income approach. If the result of the valuation of the controlling interest, carried out under the income approach has gone beyond the specified range, the final result of evaluation will be the closest to this result (top or bottom) of the specified range. The difference between the proposed approach (estimation of the final result) from the traditional, obviously, is the implementation of additional calculations using the method of liquidation value, or the substitution method (modified cost approach), which, of course, increases the complexity of the calculations. However, the increased complexity of the calculations in the evaluation of controlling interests seems justified because "worth it" - this is achieved by increasing the validity of the total value in a situation where at stake are usually a lot of money [11].

The valuation of non-controlling interests depends on whether these shares quoted shares or not. In the case, when the non-controlling interests are quoted shares, their value is determined by the participants of the stock market and is already a known quantity. Exceptions are cases where the assessment is made for forced foreclosure or in situations where the issuer of shares is estimated in bankruptcy: in the first case is, the value of the estimated shares cannot be lower than the pro rata share of the liquidation value of the net assets (pro rata share of the net assets of the company in liquidation); in the second case, the value is equal to a proportionate share of the net asset value upon liquidation of the company. In cases where the noncontrolling interests are not quoted shares, their total value is determined in a conventional manner on the

${ }^{3}$ In accordance with the requirements of Art. 84 of the Federal Law "On Joint-Stock Companies» №208

${ }^{4}$ Justification of this see in p. 31 Principles IVS (ed. 2011).

${ }^{5}$ Limited Liability Company-is one of the legally allowed in Russia forms registration and operation of businesses, adjustable Federal Law "On Limited Liability Companies" (FL-14). 
Citation: Kozyr YV (2015) Recommendations for Making Judgements about Total Market Value in the Evaluation of Interests in Companies. Review Pub Administration Manag 3: 161. doi:10.4172/2315-7844.1000161

Page 5 of 5

basis of a comparative, income and cost approaches using weighting procedures intermediate evaluation results. The exception is a situation where the issuer of shares is estimated in bankruptcy: in such cases, the final result of evaluation will be proportionate share of the liquidation value of the net assets.

\section{Conclusion}

Shown in Table 1 recommendations for determining the final cost of the evaluation sites, according to the author, can more accurately and reasonably determine their value (as the most probable price of the transaction) compared with widespread now traditional ways to harmonize the results of evaluation approaches.

In addition to the above-mentioned logic, common sense, is to identify overlapping ranges of acceptable prices of buyers and sellers, the proposed recommendations in most cases, to avoid the use of premiums and discounts for the presence/absence of control elements, is an independent source of subjectivism.

In conclusion, we note the following.

In addition to evaluation of interests in business/shareholdings, these recommendations can be applied in cases of evaluation of commercial real estate, since such an projects are essentially a rental business, and in relation to it these recommendations have the same treatment as to other types of business.

\section{References}

1. Kozyr YV (2012) Elements and principles of business valuation. Lambert Academic Publishing.

2. Kozyr YV, Tabakova SA (2013) Guidelines on the application of economic substitution of assets. Approved. Methodical Council of Russian society of appraisers used. Labrate.

3. Kozyr YV (2003) On the question of cost control. Esme, Moscow http://www. appraiser.ru/default.aspx?Sectionld=188\&Id=1342.

4. International Valuation Standards (2011) The Russian Society of Appraisers Moscow.

5. Saaty TL (1989) Making decisions, Analytic hierarchy process. Radio and communication, Moscow.

6. Sharpe WF, Gordon AJ, Bailey JW (1997) Investment. INFRA-M, Moscow.

7. Grigoriev AV, Kozin PA (2007) Methods of determining the values of weight coefficients under harmonization of evaluation results. Auditor sheets 2.

8. http://www.labrate.ru/kostin/064749.pdf.

9. http://mathscinet.ru/files/MirSlaev10.pdf.

10. Teveleva OV (2008) View on the problem of harmonization of evaluation results. Labrate

11. Shcherbakov VA, Shcherbakova NA (2009) The using of factor analysis under harmonization of the results of the business assessment. Siberian financial school 5: 70-73. 